Volume 1

Number 1

Fall 2016

\section{The Boller Review:}

A TCU Undergraduate Journal of Research and Creativity

\title{
Review of the Literature Regarding the Decision to Report Sexual
}

\section{Assault}

by Erica Pieper

Sexual assault victims have many choices to make. Should they receive medical treatment? How do they keep themselves from being revictimized? Do they inform law enforcement about the incident? There is a stigma that surrounds reporting this type of crime and a fear that no one will believe them. The pain, trauma, worthlessness, and other extreme emotions that stem from sexual assault are contributing factors in an individual's choice to report; there are many reasons why a person would choose not to report. From my time spent at The Women's Center of Fort Worth, I have seen survivors make this difficult decision over and over-some choosing to report, some not.

\section{Scope and Significance of the Problem}

Sexual assault victims most often are women. According to The National Intimate Partner and Sexual Violence survey, around 1 in 5 women and 1 in 71 men in the United States will be raped at some point during their lives. Around 1.27 Million women will be raped, and 6.64 Million women will experience some other type of sexual violence during their lives. These staggering numbers do not account for individuals who do not 
report. The most victimized age group is 18 - 24 years of age, with $37.4 \%$ of reports falling in that age group. The second most victimized age group is 11 - 17, with $29.9 \%$ reporting victimization at some point (American Psychological Association, 2010).

In October 2015, 65 individuals in Tarrant County sought medical attention for a sexual assault and were accompanied through this process by an advocate from The Women's Center. Victims of sexual assault are affected in many different ways: physically, mentally, emotionally, and spiritually. From personal experience with victims directly after their assaults, there is an enormous shift in one's view of the world. Because victims have been violated in such an intimate way, victims often feel consistently unsafe, even in situations or places they previously felt comfortable in. Many victims describe feeling unclean, vulnerable, extremely angry, and worthless.

To complicate these emotions further, sexual assault most often occurs between people who know each other-whether that is partners, relatives, or friends. This adds an element of guilt and confusion to a survivor's circumstances. Survivors may not want to get the perpetrator in trouble, may be embarrassed that the perpetrator is a person close to them, or perceive the perpetrator as more believable than themselves, further contributing to doubt about their self-worth (Walsh \& Bruce, 2014).

\section{Relevance to Social Work}

Choosing to report sexual assault and having a positive experience throughout the process is directly related to the social work value of social justice. Social workers are asked to advocate on behalf of vulnerable populations, specifically for those who may be 
discriminated against (NASW, 2008). Sexual assault reports should be handled in the same way as all other types of crimes-with no burden of proof lying with the victim. A survivor of sexual assault should be handled with the same regard as survivors of other crimes. I have seen that survivors of sexual assault I have interacted with through The Women's Center often doubt their value and worth as a result of their victimization, also directly threatening dignity and worth of a person, a core value stated in the NASW Code of Ethics (NASW, 2008). As a social worker, it is my responsibility to ensure that individuals' views of themselves do not further decrease as a result of the decisions they make regarding reporting their assaults.

\section{Aim of Review}

The aim of the literature review is to investigate influencing factors on sexual assault survivors' choice to report their crimes to law enforcement.

\section{Methods}

Study Inclusion Criteria

When researching the decision to report sexual assault, it is especially important to take a holistic view of the situation. I chose articles that focused not only on reporting of sexual assault to law enforcement, but also on the circumstances in which the crime took place, the nature of the offence, the parties involved, and previous victimization. I utilized studies with a sample of at least 150 participants, as each sexual assault is vastly different and this allows for a fuller understanding of the information. The studies 
chosen covered all ages, genders, races, classes, and types of sexual violence.

Four of five studies were conducted in the United States, the fifth being conducted in Oslo, Norway. Including a study from outside the United States allows for a larger perspective on the issues regarding reporting sexual assault. Each study was conducted in a different location, and the samples are considered representative of the populations. The locations include nationwide, statewide, citywide, university-wide, and agency-wide. This allowed for a comprehensive review and comparison of the literature. Each study had been conducted within the past, ten years which allows for a relevant view of the issues surrounding sexual assault reporting.

Outcome variables in the studies covered a wide range of topics: reporting sexual assault, mental health issues, substance abuse, who reported the crime, utilization of medical care, and participation in risky behaviors. Because of the range in topics covered in the studies, both qualitative and quantitative data was gathered.

Identification of Studies

To locate studies for the literature review, I used ESBCO Host, specifically SocINDEX with Full Text Advanced Search. Because this literature review had a very specific focus, SocINDEX was especially helpful in locating social work specific research on this topic. To narrow down my search I used phrases such as "sexual assault," "reporting," "mental health," and "law enforcement." 
Data Extraction

Data extracted from each article includes the author and year published. Next, the research design, as well as the study setting, is described in detail. The independent and dependent variables are identified, and the sample size and description are explained explicitly. Next, each of the measures in the study is listed, along with an explanation for their use. The method of data collection is stated, followed by a detailed analysis of how the data was analyzed. Lastly, major findings of each study are stated.

\section{Description of Articles}

There is a wealth of knowledge surrounding the effects of sexual assault, yet little research has been done on what factors play into a victim's decision to report. Many variables such as gender, class, race, relationship with offender, and circumstance of the sexual assault influence this choice. It was important to utilize articles that gave notice to each of these variables.

\section{Target Audience}

Sexual assault is a crime that most often affects women. In four of the five studies, the majority of participants were female (Walsh \& Bruce, 2014; McFarlane et al., 2005; Kapur \&Windish, 2010; Nesvold, Ormstad, \& Friis, 2011). There was also a study included in which males and females are equally represented (Felson \& Pare, 2005). Regarding race, three of the studies primarily had participants who identified as White (Walsh \& Bruce, 2014; Felson \& Pare, 2005; Kapur \&Windish, 2010), and one 
study primarily had participants who identified as Black (McFarlane et al., 2005). The fifth study did not include demographic questions regarding race (Nesvold, Ormstad, \& Friis, 2011). Two of the studies investigated the victims' relationships to the perpetrators, both indicating the majority of participants had been victimized by an a known party: partner, ex-partner, family member or friend (McFarlane et al., 2005; Felson \&Pare, 2005).

\section{Measures}

In each of the studies utilized for this literature review, a demographic questionnaire gathering information regarding gender and race was used (Walsh \& Bruce, 2014; McFarlane et al., 2005; Kapur \&Windish, 2010; Nesvold, Ormstad, \& Friis, 2011; Felson \& Pare, 2005). Otherwise, the same measures were not used in any of the observed studies.

There were numerous measures used in each of the studies, one being the PTSD Checklist (PCL). This allows the participant to self-report emotions felt within 48-hours of the unwanted sexual experience, such as anxiety or anger (Walsh \& Bruce, 2014). Another measure used is the Depression Anxiety Stress Scales-21 (DASS-21), which asks participants to self-report levels of depression, anxiety, and stress (Walsh \& Bruce, 2014). The Posttraumatic Cognitions Inventory (PTCI) is used as a means to gather information about world beliefs, self-worth, and self-blame (Walsh \& Bruce, 2014). The RCP Questionnaire gathers information as to why victims did or did not choose to report their sexual assaults to law enforcement (Walsh \& Bruce, 2014). 
The Danger Assessment Scale is used to determine participants' death risk following their assaults (McFarlane et al., 2005). Lastly, the Connecticut Behavioral Risk Factor Surveillance System (CT-BRFSS) was used to contact residents of Connecticut regarding their health and medical usage (Kapur \&Windish, 2010). Outside of these measures, the studies used for this literature review applied their personally developed questionnaires or surveys (Walsh \& Bruce, 2014; McFarlane et al., 2005; Kapur \&Windish, 2010; Nesvold, Ormstad, \&Friis, 2011; Felson \& Pare, 2005).

\section{Target Setting}

To provide a wide perspective, each study was conducted in a different geographical location as well as a different agency setting. The smallest study used in this literature review, conducted by a district attorney's office in the United States, included 150 participants, each of whom reported his or her assault to the police. This district attorney's office that conducted this study is located in a large city and serves a diverse population (McFarlane et al., 2005). The National Violence Against Women Survey conducted the largest study used in this literature review, surveying 16,000 participants. This nationwide survey randomly sampled and contacted United States citizens over 18 years old; participants were asked if they had ever been sexually assaulted and if so, if they had reported the incident to the police (Felson \& Pare, 2005).

There is one study included in the literature review that was not conducted in the United States. This study took place in Oslo, Norway at a sexual assault center of an outpatient emergency ward. A sample of 354 individuals participated in this study. This 
allowed for a comparison between the United States and Norway in reporting experiences (Nesvold, Ormstad, Friis, 2011).

\section{Results}

When victims make the decision to report sexual assault, there are numerous factors they take into consideration. These factors include, but are not limited to, whom the offender was, how long ago the event happened, the support system they have in place, their perception of safety, trauma symptoms experienced due to the event, and their assurance that they will be believed if they tell someone. These factors can be summarized in three categories: physical, mental and emotional effect, and social. There is not one single factor that contributes to all sexual assault victims' reporting decision.

Physical

The decision to report based on physical circumstances was investigated by three of the studies utilized for this literature review. It was found that victims were more likely to report if they experienced some sort of physical injury from the attack (Nesvold, Ormstad, \& Friis, 2011). Additionally, victims in another study reported being unlikely to have seen a physician in the past 12 months, due to medical costs, as compared to those who had not experienced sexual assault (Kapur \&Windish, 2010). Victims who experienced more than one sexual assault were more likely to report, as compared to victims who experienced only one (McFarlane et al., 2005). After reviewing the physical circumstances that influence reporting, it is understandable as to why this is a difficult decision to make. 
Mental and Emotional

The most complex reasons one may choose or choose not to report can be related to mental and emotional effects. PTSD has been found to have a significant impact on the decision to report-those who experience hyper vigilance, anxiety, panic attacks, and other similar symptoms are more likely to make a police report (Walsh \& Bruce, 2014). However, it was also found that depressive symptoms did not predict differences in reporting decisions (Walsh \& Bruce, 2014). Many victims stated their main reason for not reporting was that the event was too minor, or that it was easier to minimize the event than to report it (Felson \& Pare, 2005). Minimizing or internalizing the event leads to further emotional turmoil, leading the victim far from his or her path to healing.

Social

The social reasons are seemingly the most influential as to why a victim may or may not decide to report. In four of the five studies reviewed, it was found that the victim was less likely to report the sexual assault if the offender was someone he or she knew (Walsh \& Bruce, 2014; McFarlane et al., 2005; Nesvold, Ormstad, \&Friis, 2011; Felson \& Pare, 2005). It was also found that young people, specifically individuals under 18 years of age, were much less likely to report when the offender is someone known, as compared to older victims (Nesvold, Ormstad, \& Friis, 2011). One of the most disturbing statistics found during this literature review was that victims are five times less likely to report the assault if the offender is a family member rather than a stranger (Felson \& 
Pare, 2005). The social constructs that keep victims from reporting are often the systems closest to them, such as family.

\section{Discussion}

Major Findings

As a whole, it is difficult to pinpoint a single reason why victims of sexual assault decide to report. However, these studies were able to provide an overview of common influencers. The most consistently stated reason for non-reporting was the victim's relationship with the offender. Someone victimized by a partner, spouse, family member, or friend is less likely to report than someone victimized by a stranger. Another common factor found in the articles was the mental effect of the sexual assault and how that influenced reporting. Those with hyper-vigilant symptoms report at much higher rates than those with depressive symptoms. Finally, it was consistently found that victims who sought medical treatment were also more likely to report.

Throughout all five of these articles, the findings were consistent. However, as mentioned earlier, there is no definite predictor of reporting. There is not one characteristic of the victim, situation, or effect of the assault that will ensure reporting or non-reporting. Deciding to report sexual assault is an individualized decision, and victims should be encouraged to do what they believe is most beneficial to them. 


\section{Limitations}

There are limitations found in each of the articles, the most noticeable being the lack of a consistent measurement tool. The studies took individual steps toward gathering new information with their personally developed questionnaires, but the lack of consistency between measures makes it difficult to compare and contrast results. In order to gather a deeper understanding of the issues surrounding reporting sexual assault, it would be beneficial to develop a scale to gauge satisfaction in the interaction with law enforcement, emotional effects on the victim, and outcomes of reporting.

Another limitation found in this research is that each article included at least one measure that required self-reporting. As an advocate at the Women's Center, it has been made clear to me that sexual assault victims have been through such severe trauma that they have difficulty in their cognitive functioning. This leads me to believe that selfreports from victims may not always be extremely accurate, as the victim is experiencing a shock to his or her physical, mental, and emotional well-being.

Yet another limitation of the research is the time of data collection. One study surveyed the victim's emotions immediately following the sexual assault, but collected this information at a retrospective date (Walsh \& Bruce, 2014). Another article included information gathered directly after the assault when the victim sought medical attention (Nesvold, Ormstad, Friis, 2011). Difference between the times of data collection can lead to inconsistent and non-comparable information. 
Future Research

There is little research to be found that directly investigates the effects of reporting sexual assault crimes to law enforcement. In order to further this research and better assist victims of sexual assault, it would be productive to develop a universal measure of physical, mental, and emotional status prior to reporting and after reporting. This would not only give feedback to law enforcement officers regarding their ability to exercise sensitivity toward victims, but also would allow for helping professionals, such as social workers and therapists, to better serve and provide resources to victimscatered to whether or not they report their assault.

Agency Implications: Practice

The results of the literature review gives new insight to the reporting process our clients may decide to participate in. There are no requirements in place for victims to report their sexual assaults to the police in order to receive services from The Women's Center (TWC). Victims who do not report right after their assault become less likely to report as time passes due to an increased belief that no one will believe them (Nesvold, Ormstad, Friis, 2011). It is important for therapists and advocates at TWC to keep this in mind when working with victims for numerous reasons: so as not to make the victim feel disbelieved simply because of lack of reporting, to affirm the choice to share the story of his or her sexual assault, and to understand the time policies that surround reporting. 
Agency Implication: Policy

The Women's Center works to assist survivors of sexual assault on their path to healing. This begs the question - how can practitioners best assist them? Because there is a lack of consistency in research, it is impossible to encourage or discourage a victim to report with the guarantee that he or she will positively benefit. Knowing this, it is important for therapists and advocates to encourage victims to do what they see as best for themselves in regard to reporting. It is also important for those in the helping profession to be familiar with the reporting process and procedures so as to allow victims to make informed decisions. 


\section{References}

Felson, R. B., \&Paré, P. (2005). “The Reporting of Domestic Violence and Sexual Assault by Nonstrangers to the Police.”J ournal Of Marriage \& Family, 67(3), 597-610. doi:10.1111/j.1741-3737.2005.00156.x

Kapur, N. A., \& Windish, D. M. (2011). "Health Care Utilization and Unhealthy Behaviors Among Victims of Sexual Assault in Connecticut: Results from a Population-Based Sample." J ournal Of General Internal Medicine, 26(5), 524530. doi:10.1007/ s11606-010-1614-4

McFarlane, J., Malecha, A., Gist, J., Watson, K., Batten, E., Hall, I., \& Smith, S. (2005). "Intimate Partner Sexual Assault Against Women and Associated Victim Substance use, Suicidality, and Risk Factors for Femicide.” Issues In Mental Health Nursing, 26(9), 953-967. doi:10.1080/01612840500248262

National Association of Social Workers. (2008). Code of Ethics. Retrieved from http:// www.naswdc.org/ pubs/ code/ code.asp

Nesvold, H., Ormstad, K., \& Friis, S. (2011). “Sexual Assault Centers and Police Reporting—An Important Arena for Medical/ Legal Interaction.” J ournal Of Forensic Sciences, 56(5), 1163-1169. doi:10.1111/j.1556-4029.2011.01880.x

Pushing the Prevention Envelope. (2010). Family Violence Prevention \& Health Practice, 1(9), 5.

Walsh, R. M., \& Bruce, S. E. (2014). “Reporting Decisions after Sexual Assault: The Impact of Mental Health Variables." Psychological Trauma: Theory, Research, Practice, and Policy, 6(6), 691-699. doi:10.1037/a0036592 